\title{
UN BALANCE DE LA NEGOCIACIÓN COLECTIVA Y SU RELACIÓN CON LA ORGANIZACIÓN SINDICAL EN ARGENTINA (2003-2015)
}

\section{Clara MARTICORENA*}

RESUMEN: El aumento de la negociación colectiva operado desde el año 2003 en Argentina dio lugar a diversos estudios centrados en el análisis de sus determinantes políticos, institucionales y económicos o bien enfocados en el estudio de su evolución y características generales. Las investigaciones se centraron en la evolución cuantitativa de las negociaciones y en su periodicidad, desplazando el estudio de los procesos de negociación y contenidos negociados. En este artículo precisamos una serie de elementos teóricos que suelen quedar relegados en los debates sobre la temática y realizamos un balance de la negociación colectiva en el período para luego reflexionar sobre el vínculo entre los procesos de negociación y la organización sindical de los trabajadores.

PALABRAS CLAVE: Negociación colectiva. Organización sindical. Legalidad industrial. Postconvertibilidad. Argentina.

\section{Introducción}

El presente artículo se propone realizar un balance de la negociación colectiva en Argentina durante los años 2003-2015, período particularmente destacado en cuanto a la cantidad y dinámica de las negociaciones en nuestro país ${ }^{1}$. Más allá

\footnotetext{
CEIL-CONICET - Centro de Estudios e Investigaciones Laborales-Consejo Nacional de Investigaciones Científicas y Técnicas. Buenos Aires - Argentina. C1083ACA - cmarticorena@ceilconicet.gov.ar.

1 La historia de la negociación colectiva en la argentina ha estado signada por las interrupciones. Desde el año 1953 -año en que se sanciona la Ley de Convenciones Colectivas de Trabajo, № 14250-
} 


\section{Clara Marticorena}

de esta constatación empírica, es decir, más allá del aumento cuantitativo de las negociaciones colectivas con respecto a la propia historia de la negociación colectiva en la Argentina, los estudios del período muestran diversas falencias. En general, han sido relegados los problemas teóricos vinculados a la negociación colectiva así como también aquellos vinculados a los procesos de negociación y contenido de las negociaciones.

Reconociendo estas falencias, nuestra investigación pretende aportar una mirada que integre estas dimensiones sobre la base del análisis de convenios y acuerdos colectivos y de entrevistas a representantes sindicales, empresarios y funcionarios del Ministerio de Trabajo, Empleo y Seguridad Social (MTESS) de distintos sectores de la industria manufacturera, sector que concentró la mayor parte de las negociaciones del período ${ }^{1}$.

El significativo aumento y dinamismo de la negociación colectiva operado a partir de los años 2003 y 2004 dio lugar a diversos análisis que tendieron a resaltar sus diferencias respecto de las características configuradas en la década anterior ${ }^{2}$. La contraposición fue construida fundamentalmente sobre la base de una evaluación cuantitativa, resaltando el aumento en la cantidad de negociaciones y su rol en la determinación salarial, tendiendo a permanecer desplazada la consideración del carácter de la negociación salarial y de los contenidos no salariales negociados. Como apuntamos en diversos trabajos, se trata de un aspecto sustancial dado que constituye un problema asumir que el aumento de la negociación colectiva implica por sí mismo o se traduce automáticamente en una modificación de las características configuradas en los años ' 90 .

Efectivamente, desde nuestra perspectiva, la negociación colectiva ha sido clave durante estos años para ordenar desde el Estado las relaciones laborales en un

estuvo sistemáticamente interrumpida o limitada por dictaduras o gobiernos democráticos. Luego de su suspensión durante la última dictadura cívico-militar en 1976, no se abrió una nueva ronda de negociación hasta 1988, es decir, 5 años después del retorno de la democracia en 1983. A partir de esta ronda, la negociación colectiva funcionó ininterrumpidamente hasta la actualidad. Durante los años '90 fue un mecanismo privilegiado a través del cual se buscó no sólo legalizar sino también legitimar las políticas de flexibilización laboral. De todos modos, la cantidad de negociaciones aumentó significativamente a partir del año 2003 y 2004, dinámica que se encuentra vinculada no sólo al aumento del empleo sino también a la dinámica inflacionaria que marca el desenvolvimiento de la lucha económica a partir de la caída de la convertibilidad. De este modo, mientras que en la década del ' 90 las negociaciones se ubicaban en torno o por debajo de las 200, durante la postconvertibilidad se incrementaron significativamente (CUADRO No 1). Puede consultarse, al respecto, Marticorena (2014a 2014b) y Boletín de Estadísticas Laborales (MTESS).

1 El estudio, plasmado en mi tesis doctoral y continuado posteriormente, se ha centrado en diversos sectores de la industria manufacturera, sector que concentró la mayor cantidad de negociaciones del período. Además de un análisis agregado, hemos profundizado el estudio en los siguientes sectores: alimentación, aceiteros, automotriz, panadero, químico y petroquímico, textil y vestido, estudiando en forma pormenorizada los convenios colectivos de trabajo y actas acuerdo negociadas en durante la postconvertibilidad. Para mayores precisiones metodológicas véase Marticorena (2014a).

2 Por ejemplo, Palomino y Trajtemberg (2006) y Senén González, Trajtemberg y Medwid (2010). 


\section{Un balance de la negociación colectiva y su relación con \\ La organización sindical en Argentina (2003-2015)}

momento inicial de recomposición de la acumulación, de crecimiento económico y del empleo. Pero, al mismo tiempo, el dinamismo asumido por las negociaciones colectivas a lo largo de la última década ha operado como un factor significativo en el impulso de la organización sindical en general, y de base en particular.

Luego de repasar el análisis del contenido y la estructura de la negociación colectiva, sus continuidades y rupturas con respecto a los años ' 90 , en este escrito nos interesa reflexionar sobre el vínculo entre el proceso de negociación y la organización de los trabajadores, planteando algunas hipótesis que serán eje de futuras indagaciones. Veamos en primer término algunas consideraciones teóricas sobre las relaciones laborales y la negociación colectiva que consideramos fructíferas para el análisis y que suelen estar ausentes de los estudios sobre la temática.

\section{La negociación colectiva: ¿democracia industrial o legalidad industrial?}

Nuestra perspectiva considera la importancia de analizar la negociación colectiva restituyendo su vínculo con la dinámica de la lucha de clases, dimensión que los enfoques institucionalistas no se plantean. Es en este sentido que estudiamos la estructura de la negociación colectiva y los contenidos de acuerdos y convenios colectivos de trabajo, considerando que sus cambios y/o continuidades en el tiempo pueden ser analizados como una suerte de termómetro de la correlación de fuerzas entre las clases sociales.

Ahora bien, la propia forma de la negociación colectiva constituye un modo de institucionalización de la lucha de clases (HYMAN, 1981), que 1leva inscripto y vehiculiza el control del capital sobre el trabajo, por cuanto aquello que se discute y resulta objeto de negociación es la forma, los alcances y límites, que adopta la explotación del capital sobre el trabajo y no la explotación misma (MARTICORENA, 2014a).

Dicho esto, resulta necesario plantear que la negociación colectiva se ha constituido históricamente como modo de control del conflicto laboral, pero también como modo de limitar el despotismo patronal. Es en este sentido que recuperamos el concepto de legalidad industrial de Gramsci (1991), contraponiéndolo a la concepción de la negociación colectiva como imperio de la democracia industrial proveniente del pluralismo anglosajón (ACKERS, 2007; DABSCHECK, 1989; CLEGG, 1985; FLANDERS y CLEGG, 1956).

La noción de legalidad industrial en Gramsci (1991) expresa la conquista del reconocimiento de un conjunto de condiciones de trabajo por parte de la patronal a través de la acción de los sindicatos en tanto organización corporativa de la clase 
obrera. Es decir, representa a los obreros en su condición de vendedores de fuerza de trabajo. Esta legalidad industrial, es también la que supone su reproducción como proletariado, como clase dominada y subordinada al capital. De este modo, la negociación colectiva permite establecer límites a la unilateralidad del despotismo patronal al tiempo que presupone la legitimación de la explotación del trabajo por el capital y su control del proceso productivo.

La posibilidad de que a través de la negociación colectiva los trabajadores puedan limitar el avance patronal depende de la correlación de fuerzas entre las clases sociales en momentos históricos determinados. Efectivamente, así como los convenios y acuerdos colectivos han reflejado distintas conquistas de los trabajadores en momentos de ascenso de la lucha de clases, también han sido vehículo de la pérdida de derechos y condiciones previamente conquistadas. Un ejemplo de ello podemos observarlo si tenemos en cuenta que durante la década del ' 90 en la Argentina, en el marco de una correlación de fuerzas ampliamente desfavorable para los trabajadores por el avance de la precarización laboral y el alto desempleo, la negociación colectiva fue una herramienta para introducir y legitimar formas de flexibilización laboral.

Nuestra perspectiva se diferencia, así, de las visiones pluralistas -hegemónicas en el campo de estudios de las relaciones laborales- según las cuales la negociación colectiva constituiría una expresión de la democracia industrial, donde no se reconoce el dominio del capital sobre el trabajo, sino que se asume que patrones y trabajadores son capaces de acordar condiciones de trabajo en igualdad de condiciones. Como señalaba Hyman (1981), los pluralistas no observan el orden y el consenso en la industria como resultado del ejercicio del poder del capital, sino como expresión de la cooperación de trabajadores y capitalistas.

El desarrollo histórico de las instituciones laborales permite, de hecho, constatar en diversos países de qué modo el mecanismo de la negociación colectiva fue alentado desde las clases dominantes como modo de regulación del conflicto laboral en vistas a lograr la "paz industrial". Sin embargo, los procesos de institucionalización, dominio y control sobre los trabajadores nunca están exentos de resistencias y deben ser analizados históricamente. Efectivamente, la "institucionalización del conflicto laboral logra de hecho una contención provisional del desorden..." (HYMAN, 1981, p. 219).

Inspirados en estas discusiones, y a la luz de los debates acerca de la revitalización sindical en la Argentina a partir del año 2003, nos interesa rastrear el vínculo entre los procesos de negociación colectiva y la organización sindical, observando no sólo la dinámica a través de las cúpulas sindicales, si no incorporando una mirada que sitúe el interés en los procesos de negociación colectiva, indagando de qué modo la negociación colectiva impulsó la vida interna de los sindicatos y la 


\section{Un balance de la negociación colectiva y su relación con \\ La organización sindical en Argentina (2003-2015)}

organización de base, cómo opera concretamente la institucionalización del conflicto laboral y las tensiones que atraviesa.

\section{Continuidades y cambios en relación con los años de consolidación neoliberal}

Realizar un balance de la negociación colectiva en Argentina en el período 2003-2015 requiere abordar sus características generales, pero también la identificación de distintos momentos y dinámicas en relación con los cambios en las condiciones económicas y políticas a lo largo de un período que se inicia con la crisis de la convertibilidad y, con ella, con la crisis del consenso neoliberal que tuvo su apogeo durante la década del '90.

Como señalamos en otros escritos, los estudios sobre la temática han tendido a privilegiar una mirada cuantitativa y general, desplazando el análisis de las características, contenido y procesos de negociación. Precisamente, nuestra investigación ha permitido introducir en el debate sobre la negociación colectiva y revitalización sindical diversos contrapuntos que marcaron significativas líneas de continuidad con respecto a la dinámica de las relaciones laborales en la etapa de consolidación neoliberal. Estos contrapuntos se refieren fundamentalmente a la estructura de la negociación colectiva (vinculada al nivel de negociación), al tipo de negociación predominante, y a los contenidos de la negociación.

En cuanto a la estructura de la negociación, a pesar de observarse un aumento de las negociaciones a nivel de actividad, las negociaciones por empresa continuaron predominando dentro del total, manteniendo la inversión de la proporción de negociaciones por actividad y empresa observable desde comienzos de los años ' 90 .

$\mathrm{Al}$ respecto, cabe mencionar que en la ronda de negociaciones del año 1988 tan sólo el $19.4 \%$ de las negociaciones se celebró por empresa. Con el avance de la descentralización de la negociación colectiva durante los años '90, en el período 1995 - 1999, el 76,6\% de las negociaciones se celebraron en dicho nivel. Si bien a partir del 2004 la legislación laboral otorgó renovada importancia a las negociaciones de actividad, las negociaciones de empresa continuaron teniendo un claro predominio dentro del total (CUADRO 1).

Por su parte, la negociación colectiva en el período ha sido fundamentalmente salarial, característica reflejada en la importancia de los acuerdos frente a la negociación de convenios colectivos de trabajo ${ }^{3}$ (CUADRO 1).

\footnotetext{
3 Mientras los convenios colectivos de trabajo son cuerpos completos de normas que regulan el conjunto de las relaciones laborales, las actas acuerdo incluyen modificaciones puntuales para el mismo ámbito y firmado por las mismas partes del convenio original (NOVICK y TRAJTEMBERG, 2000).
} 


\section{CUADRO 1: Negociación colectiva en Argentina según tipo y nivel de negociación (2003-2015)}

\begin{tabular}{|c|c|c|c|c|c|}
\hline \multirow{2}{*}{ Año } & \multirow{2}{*}{$\begin{array}{c}\text { Cantidad } \\
\text { total de } \\
\text { negociaciones }\end{array}$} & \multicolumn{2}{|c|}{$\begin{array}{c}\text { Tipo de negociación (\%) } \\
\text { Convenios } \\
\text { colectivos }\end{array}$} & Acuerdos & Nivel de negociación (\%) \\
\hline 2003 & 406 & $32,7 \%$ & $67,3 \%$ & $16,7 \%$ & $83,3 \%$ \\
\hline 2004 & 348 & $25,3 \%$ & $74,7 \%$ & $32,2 \%$ & $67,8 \%$ \\
\hline 2005 & 568 & $18,4 \%$ & $81,6 \%$ & $35,7 \%$ & $64,3 \%$ \\
\hline 2006 & 930 & $15,0 \%$ & $85,0 \%$ & $34,9 \%$ & $65,1 \%$ \\
\hline 2007 & 1027 & $14,4 \%$ & $85,6 \%$ & $32,7 \%$ & $67,3 \%$ \\
\hline 2008 & 1231 & $8,3 \%$ & $91,7 \%$ & $35,4 \%$ & $64,6 \%$ \\
\hline 2009 & 1331 & $6,4 \%$ & $93,6 \%$ & $29,8 \%$ & $70,2 \%$ \\
\hline 2010 & 2038 & $6,5 \%$ & $93,5 \%$ & $28,6 \%$ & $71,4 \%$ \\
\hline 2011 & 1864 & $5,7 \%$ & $94,3 \%$ & $28,0 \%$ & $72,0 \%$ \\
\hline 2012 & 1744 & $3,7 \%$ & $96,3 \%$ & $30,5 \%$ & $69,5 \%$ \\
\hline 2013 & 1699 & $4,1 \%$ & $95,9 \%$ & $30,6 \%$ & $69,4 \%$ \\
\hline 2014 & 1963 & $5,1 \%$ & $94,9 \%$ & $27,3 \%$ & $72,7 \%$ \\
\hline 2015 & 1957 & $5,3 \%$ & $94,7 \%$ & $27,5 \%$ & $72,5 \%$ \\
\hline
\end{tabular}

Fuente: Elaboración propia en base a MTEySS.

El hecho que se negocien fundamentalmente condiciones salariales refleja, efectivamente, un aumento de la conflictividad laboral pero también la fuerte caída salarial real producto de la devaluación de enero de 2002, en torno al $35 \%$, y la dinámica inflacionaria posterior, acelerada a partir del año 2007. El estudio de los contenidos salariales negociados, los niveles alcanzados y la composición de la clase trabajadora muestran que más que un avance es preciso hablar de recuperación en un marco de fuerte heterogeneidad dada por niveles muy elevados de empleo no registrado y condiciones precarias de empleo y contratación. El empleo no registrado presentó una tendencia ascendente desde la década del ' 80 en Argentina y alcanzó su nivel más elevado en el año 2003 llegando al 49.2\% de los asalariados. Si bien luego presentó una evolución decreciente, a partir del 2010 tendió a mantenerse en torno al $35 \%$ de los asalariados ${ }^{4}$.

\footnotetext{
4 Puede consultarse, al respecto, Marticorena (2014a) y (2015a).
} 


\section{Un balance de la negociación colectiva y su relación con \\ La organización sindical en Argentina (2003-2015)}

Diversos estudios ${ }^{5}$ señalaron cambios sustantivos en la dinámica del empleo y las relaciones laborales durante la postconvertibilidad, sin indagar detenidamente las características que adquirió la negociación salarial ni qué ocurrió con respecto a los contenidos ligados a la flexibilización laboral incorporados a través de la negociación colectiva en los años ' $90^{6}$. Sintetizamos aquí brevemente los resultados de nuestra investigación al respecto.

\section{3. a. La negociación salarial ¿indicador de un aumento del poder de los trabajadores?}

La importancia adquirida por los contenidos salariales debe ser analizada en el marco de la profunda caída de los salarios reales que se produjo a partir de la devaluación del peso en enero de 2002, y de la configuración de una dinámica inflacionaria en el marco del significativo crecimiento de la economía y del empleo. Deben considerarse también transformaciones políticas significativas, como la resistencia a los procesos de ajuste neoliberal manifiesta durante la crisis de la convertibilidad y expresada en diciembre del año 2001, en un ciclo de ascenso de la conflictividad que se desacelera en los años 2002 y 2003 pero vuelve a ascender en los años 2004 y $2005^{7}$.

El análisis de la negociación salarial nos permitió observar la batalla que entablan los trabajadores, no sólo por recuperar y mantener su poder adquisitivo, sino por sus derechos, vinculados, entre otros aspectos, al rechazo a las sumas en negro, no remunerativas, no incorporadas al salario básico. De hecho, se puede observar un abanico de ítems en la composición salarial, que manifiesta las dificultades que enfrentan los trabajadores en la lucha económica.

De todos modos, la dinámica de las negociaciones y su periodicidad ha habilitado la construcción de reclamos y reivindicaciones sectoriales a los gremios (y también a las patronales), que marca el tránsito por diversas modificaciones a lo largo del período aquí analizado. El dinamismo de la negociación colectiva

\footnotetext{
5 Palomino y Trajtemberg (2006); Etchemendy y Collier (2007); Senén González, Trajtemberg y Medwid (2010), entre otros.

6 Por flexibilización laboral nos referimos a todos aquellos aspectos que permitan un mayor control patronal de las formas de contratación y uso de la fuerza de trabajo: la posibilidad de modificar la organización del tiempo de trabajo y la asignación de tareas; flexibilizar las condiciones salariales articulándolas a distintos incentivos por "desempeño", productividad, cumplimiento de objetivos; formas de contratación por tiempo determinado, personal tercerizado o contratado por agencias como estrategia permanente de "regulación" del plantel de trabajadores en función de la demanda, etc. Para un análisis detallado acerca de esta noción puede consultarse Marticorena (2014a).

7 Al respecto puede consultarse Cotarelo (2016), Atzeni y Ghigliani (2008), Eskenazi (2011); Longo (2012); Payo Esper (2014).
} 
durante la postconvertibilidad, en paritarias periódicas, facilitó la configuración de estrategias patronales y sindicales en la negociación que superan la coyuntura anual.

Es posible observar que inicialmente los aumentos del salario nominal incorporaron las sumas no remunerativas establecidas por los decretos estatales que formaron parte de la política salarial desplegada desde el año 2002, incorporándose al salario básico ${ }^{8}$. Esta incorporación se configuró en cuotas y si bien el aumento de los salarios básicos fue determinando progresivamente los niveles salariales de los trabajadores registrados, el otorgamiento de sumas no remunerativas mantuvo una importante vigencia. También, entre los contenidos salariales se destacaron los premios, gratificaciones extraordinarias o sumas por única vez.

Es preciso mencionar que la evolución de los salarios se vio limitada a partir del año 2006 en virtud de la conformación de una pauta salarial, como modo de limitar las conquistas salariales de los trabajadores en el marco de un aumento del conflicto laboral y la puja distributiva. La información analizada permite apreciar que la absorción de sumas al salario básico perdió peso en virtud de la mayor importancia de las sumas a cuenta de futuros aumentos. A su vez, se afianzó la modalidad de la negociación de aumentos en cuotas, resultando generalmente un porcentaje de aumento global menor al pactado. Cabe apuntar, de todos modos, que en algunas negociaciones los trabajadores han logrado incluir una cláusula específica sobre la no absorción de aumentos ya otorgados ni de futuros incrementos, indicio de pequeños cambios en la correlación de fuerzas entre trabajadores y empresarios.

Sintetizando, luego de un primer momento de recuperación salarial caracterizado por el blanqueo e incorporación de sumas al básico de convenio se produjo un reajuste de salarios frente a la evolución de la inflación, al menos como característica general, más allá de la capacidad de algún gremio determinado de conquistar un mayor aumento?.

En cuanto a la composición salarial, se aprecia la permanencia de cláusulas que atan parte del salario a determinadas pautas de productividad u objetivo (ya sea individual y/o grupal) o bien al desempeño. Además de ello, los salarios no sólo suelen computar la antigüedad y premios por presentismo, sino también diversos adicionales por tipo de tarea (plus trabajador polivalente), plus por turno (nocturno, rotativo, americano), adicional llamada, entre otros, que muchas veces no se encuentran expresados como un porcentaje sobre el básico sino que consisten en una suma fija que los obreros deben renegociar junto con cada nueva ronda paritaria.

\footnotetext{
8 Un detalle de la política salarial y un análisis pormenorizado de los contenidos negociados puede consultarse Marticorena (2005, 2014a, 2015b).

9 De acuerdo con Campos y Campos (2011) entre 2007 y 2010 tendió a detenerse la recuperación real de los salarios básicos tomados en conjunto dado que los aumentos pactados tendieron a situarse por debajo o en el mismo nivel que la inflación anual (considerando un índice alternativo al medido por el INDEC). Ver también Marticorena (2015a).
}

134 Estud. sociol. Araraquara v.22 $\quad$ n.42 $\quad$ p.127-144 jan.-jun. 2017 


\section{Un balance de la negociación colectiva y su relación con \\ La organización sindical en Argentina (2003-2015)}

También es usual que los distintos componentes no se detallen separadamente en los recibos de sueldo, dificultando el control del trabajador de los ítems componentes de su salario.

\section{3. b. Las condiciones de trabajo y contratación: con la marca del disciplinamiento neoliberal}

En cuanto a las condiciones de contratación, tanto el análisis de convenios y acuerdos, como de las entrevistas realizadas, evidenció la amplia y arraigada difusión de diversas modalidades de contratación por tiempo determinado, como contratos de trabajo eventual, por temporada, o por obra, modalidades que suelen utilizarse como modo de reducir costos laborales. También es posible apreciar la permanencia de estrategias de subcontratación y tercerización, ya sea a partir de su incorporación explícita en la negociación colectiva o bien a partir de las categorías de trabajadores fuera de convenio.

De todos modos, se observan ciertos cambios en las condiciones aplicadas en los casos de subcontratación o bien a través de contratos de trabajo por tiempo determinado, por ejemplo, aplicando las condiciones de convenio a trabajadores subcontratados u otorgando algún beneficio a trabajadores eventuales o temporarios en el plazo del contrato, sin que se aprecie una clara reversión de estas condiciones de contratación en sí mismas.

Sobre las condiciones de uso de la fuerza de trabajo, las cláusulas vinculadas al tiempo de trabajo manifiestan fuertes líneas de continuidad con respecto a las condiciones de flexibilidad impuestas de hecho y de derecho en los años '90. Las modificaciones más destacadas introducidas en los años '90 sobre el tiempo de trabajo se vincularon con mecanismos de cálculo de jornadas en base a promedios ${ }^{10}$ y con la posibilidad de disminuir o extender la jornada diaria; con la mayor disponibilidad patronal para efectuar cambios de turnos; con el énfasis en el carácter continuo de la tarea (debiendo el trabajador esperar el reemplazo hasta determinada cantidad de horas); y con la distribución de los descansos (permitiendo agruparlos en algunos casos y/o disponiendo su momento de goce en función de las necesidades de la producción, e incluso limitando su integración a la jornada laboral).

\footnotetext{
${ }^{10}$ Este mecanismo de definición de la jornada consiste en un instrumento privilegiado para eludir el pago de horas extra. A través de dicho mecanismo se crea un banco de horas y se generan horas en débito y crédito por parte de los trabajadores. Una vez establecida la jornada promedio, las horas pueden distribuirse entre cada jornada diaria en función de la disposición patronal. En momentos de auge de la producción permite extender la jornada reduciendo el pago de horas extra y en momentos de reducción de la demanda permite disminuir la jornada. En este caso puede suceder que el obrero deba horas a la empresa y por tanto tenga que compensarlas bajo distintas modalidades que suponen, a la vez, una nueva extensión de la jornada sin pago de horas extra.
} 
Durante la postconvertibilidad observamos, de todos modos, algunas redefiniciones con respecto al tiempo de trabajo en casos puntuales, por ejemplo, sobre los descansos o el tiempo de espera del relevo, que expresan el planteo de ciertos límites a los avances previos en la disponibilidad patronal sobre el tiempo de trabajo pero que al mismo tiempo se emplazan sobre dicho retroceso.

Un punto que creemos significativo señalar radica en que en entrevistas realizadas se plantea la conquista de aumentos salariales ligada a una mayor intensificación del tiempo de trabajo, aspecto que consideramos debe estar presente en el análisis del contenido de la negociación colectiva reciente. La compensación monetaria de extensas jornadas laborales e incluso de condiciones de trabajo insalubres (en muchas ocasiones no declaradas como tales) constituye una modalidad recurrente. En este sentido, la recomposición salarial no ha permanecido ajena a procesos de intensificación del tiempo de trabajo ya sea por la implementación de turnos rotativos, del turno americano ${ }^{11}$ (o cuarto turno) o bien por la realización de horas extra.

Otro punto abordado ha sido el de la movilidad funcional y la definición de las categorías. Al respecto, en los '90 se observa un avance en la des-fijación de los trabajadores de las tareas y funciones previamente asignadas, y estas condiciones no muestran cambios significativos en los años de la postconvertibilidad en la "letra" de convenios y acuerdos, sino más bien, parecen ser formas de gestión de la fuerza de trabajo que permanecen arraigadas en los años recientes.

Tanto en las condiciones salariales como de trabajo, a lo largo del período se fueron consolidando diferencias sectoriales vinculadas estrechamente con la orientación más o menos combativa, o más o menos colaboracionista, de las dirigencias sindicales respecto de las patronales y el Estado. Ello ha estado vinculado, a su vez, al avance de comisiones internas, cuerpos de delegados y/o líneas sindicales internas opositoras a las tradicionales dirigencias peronistas, con perspectivas antiburocráticas y a la izquierda del arco político, tanto en aquellos casos en que han logrado conquistar los sindicatos / federaciones, como por la presión que impone la situación de competencia inter e intra sindical en un contexto de crecimiento económico y baja tasa de desempleo.

\footnotetext{
${ }^{11}$ El denominado turno americano o cuarto turno posee distintas formas de implementarse pero se inscribe, como otras modalidades, en la búsqueda patronal de la adecuación de la jornada laboral al funcionamiento continuo de las líneas de producción, sobre la base de considerar la jornada semanal de trabajo y la no distinción entre horas normales y extra, ni fines de semana ni feriados. Una forma extendida se refiere a la realización de jornadas contiguas de 12 horas diarias seguidas de días francos. También puede implementarse con jornadas diarias de menor duración. Los turnos pueden (y suelen) organizarse, además, en forma rotativa, por ejemplo, mañana- tarde- noche. Bajo esta modalidad, los trabajadores realizan extensas jornadas y carecen de horario y días fijos de trabajo, lo cual no sólo deteriora profundamente sus condiciones laborales, sino también el tiempo y las condiciones de reproducción de su fuerza de trabajo, afectando su salud y su vida familiar y social.
} 


\section{Negociación colectiva y organización sindical: entre la institucionalización y la activación de las bases obreras}

Así como la dinámica y periodicidad de la negociación colectiva entre 2003 y 2015 habilitó un mecanismo que operó como ordenador y contenedor del conflicto laboral dentro de marcos institucionales, a la vez, legitimó a las organizaciones sindicales y las prácticas gremiales en los lugares de trabajo. En este escenario, el dinamismo de la negociación colectiva, al tiempo que sirvió como modo de contener y ordenar las demandas de los trabajadores, potenció no sólo el protagonismo de las dirigencias sindicales tradicionales en su papel en la disputa (y contención) de la puja distributiva, sino también del fortalecimiento de la organización sindical en los lugares de trabajo.

Si bien la información estadística es escasa y poco sistemática, relevamientos cuantitativos y distintas investigaciones de tipo cualitativo permiten observar una mayor presencia de la organización sindical en los lugares de trabajo.

La información cuantitativa proviene de relevamientos realizados por el Ministerio de Trabajo, Empleo y Seguridad Social (MTESS) en 2005, 2006 y 2008, a través del Módulo de Relaciones Laborales de la Encuesta de Indicadores Laborales. En base a esta fuente, en el año 2005 solamente el 12,4\% del total de empresas relevadas contaba con la presencia de delegados sindicales, manteniéndose en el año 2006 en ese mismo porcentaje (TRAJTEMBERG, BERHÓ, ATTORRESSI y LAUPHAN, 2005; SENÉN GONZÁLEZ, TRAJTEMBERG y MEDWID, 2010). En los establecimientos de mayor tamaño (de más de 200 trabajadores) la presencia de delegados ascendía a 61,1\%; en los establecimientos medianos (de entre 50 y 200 trabajadores) era del 31\%, mientras que sólo en el 7,5\% de los pequeños establecimientos (de 10 a 50 trabajadores) contaban con la presencia de delegados. De todos modos, el relevamiento del año 2008 permitía observar un incremento en la presencia de delegados en las empresas relevadas, alcanzando el $70 \%$ en grandes empresas, el $32 \%$ en las medianas y $11 \%$ en las pequeñas empresas (TRAJTEMBERG, SENÉN GONZÁLEZ, BORRONI y PONTONI, 2012).

Diversos estudios cualitativos en base a entrevistas a dirigentes sindicales y delegados dan cuenta, por su parte, de un aumento de delegados y comisiones internas en los establecimientos (ATZENI y GHIGLIANI, 2013; MARTICORENA y VASSALLO, 2016; VARELA, 2016).

Un modo de aproximación indirecta a los avances de la organización sindical en los lugares de trabajo ha estado dado por la evolución de la conflictividad en el lugar de trabajo, como surge de los relevamientos del Observatorio del Derecho Social de la Central de Trabajadores Argentinos - Autónoma (ODS-CTA-A, 2008) 
y del MTESS ${ }^{12}$, o bien de los "hechos de la rebelión" de los asalariados por tipo de organización, de acuerdo a los cuales Cotarelo (2016, p. 115) muestra que el porcentaje de "hechos" realizados por "cuerpo de delegados, comisión interna o línea sindical" se incrementó significativamente en la última década, siendo del $0.4 \%$ en $2002,2.8 \%$ en $2004,3.9 \%$ en $2006,11 \%$ en $2007,7.9 \%$ en 2008 , y $10 \%$ en 2009 . Claro que esto no supone necesariamente una mayor radicalidad o combatividad de las bases obreras.

La mayor presencia sindical puede verse reflejada en los acuerdos y Convenios Colectivos de Trabajo (CCT). Por ejemplo, en convenios del sector químico y textil ${ }^{13}$ celebrados entre 2008 y 2011 pudimos observar como un aspecto novedoso respecto de negociaciones anteriores de las mismas partes, la inclusión de los delegados sindicales de planta en las comisiones de seguimiento del convenio o la mención explícita de sus funciones con respecto al cumplimiento del convenio. En otros casos, como en las negociaciones celebradas por el Sindicato de Mecánicos y Afines del Transporte Automotor (SMATA), la mención de los delegados en los CCT se mantiene en las distintas negociaciones y su presencia en las plantas, reforzada por el hecho que en el sector predominan las negociaciones de empresa, no implica ni supone una mayor conflictividad obrera sino, más bien, la integración del delegado como reproductor y garante de la disciplina fabril.

Si planteamos a la negociación colectiva como forma de institucionalización de la lucha de clases pero al mismo tiempo como un mecanismo que en la coyuntura reciente pudo beneficiar el impulso de la organización sindical, cabe preguntarnos qué tipo de organización sindical se desarrolló en el período. Al respecto, mientras distintos autores plantearon que durante los últimos 15 años se asistió al surgimiento de experiencias de sindicalismo de base, antiburocrático y clasista (COTARELO, 2016; ATZENI Y GHIGLIANI, 2013; SCHNEIDER, 2013; VARELA, 2013, 2015); otros, plantearon que este sindicalismo de base sería parte de un proceso más general de activación del sindicalismo en la base del cual dicho sindicalismo de base sería una expresión estadísticamente minoritaria (SPALTENBERG, 2012).

En este punto es preciso señalar una falencia en los desarrollos sobre experiencias de sindicalismo de base en la argentina reciente, esto es, una subestimación de las experiencias de desarrollo y potenciación de la organización sindical en los

\footnotetext{
${ }^{12}$ Los informes del MTESS y del ODS-CTA-A, señalan que en los primeros años se observa el predominio de conflictos por rama de actividad por motivos salariales mientras que a partir del año 2009 la dinámica se modifica en cuanto al tipo de reclamo, apreciándose una mayor descentralización del conflicto laboral. De acuerdo al análisis del ODS-CTA-A (2008), a partir de 2009 se observa un resurgimiento de conflictos por situaciones de crisis: despidos, suspensiones, cierre de establecimientos. Estos conflictos, que en el ámbito privado se desarrollan fundamentalmente a nivel de empresa, se van a mantener a lo largo de los años siguientes, coexistiendo con los conflictos salariales por actividad.

${ }^{13}$ Se trata del CCT 1235/2011E de la empresa Basf (sector químico y petroquímico), del CCT 1039/2009E de la empresa DuPont y del CCT 1159/10E de la empresa Tipoiti (ambas del sector textil).
} 


\section{Un balance de la negociación colectiva y su relación con \\ La organización sindical en Argentina (2003-2015)}

lugares de trabajo vinculadas a las dirigencias sindicales tradicionales, es decir, de una organización sindical que tiende a reproducir a la burocracia sindical más que a combatirla o cuestionarla. Recordemos aquí que Hyman (1981) planteaba que el mismo mecanismo de la negociación colectiva impone la moderación en los reclamos obreros, en tanto impone la moderación a los líderes sindicales, incluso a los más radicalizados.

Este debate plantea la necesidad de analizar la articulación entre dinámica sindical y dinámica de la negociación colectiva sin suponer, a priori, que el impulso de la organización sindical en la base se vincula exclusivamente con sectores combativos o de izquierda, aunque sin desconocer, tampoco, su desarrollo cuantitativo e importancia cualitativa dentro del movimiento obrero. En este punto, consideramos que el desarrollo de la organización de los trabajadores en sus lugares de trabajo durante el período analizado expresa el creciente interés de los trabajadores de base de participar en la actividad sindical concibiendo la organización gremial como forma de canalizar sus reclamos y plantear sus reivindicaciones a través de la negociación colectiva. Es en este sentido que nos interesa recuperar la idea del carácter institucionalizante de la negociación colectiva respecto del conflicto laboral.

\section{Reflexiones finales}

El significativo aumento de la negociación colectiva en argentina constituye una expresión de la dinámica de las relaciones laborales durante los gobiernos kirchneristas, más precisamente, en el proceso de recomposición de la acumulación y la dominación política iniciado como respuesta a la profunda crisis del régimen de convertibilidad que estalló en el año 2001.

La negociación colectiva ha sido un mecanismo clave para el Estado en el proceso de ordenamiento del conflicto laboral y la administración de la puja distributiva por las dirigencias sindicales tradicionales. En este sentido, los contenidos negociados muestran las dificultades que han enfrentado los trabajadores en la lucha económica al tiempo que expresan la permanencia de las condiciones de trabajo impuestas por el capital a los trabajadores durante los años ' 90 . Nuestro análisis permitió apreciar cambios en las condiciones laborales a través de la negociación colectiva que no dejan de emplazarse en un trasfondo signado por el avance del capital sobre el trabajo desplegado en las últimas décadas del siglo XX. La composición salarial, la movilidad de los trabajadores entre tareas, la flexibilidad horaria, entre otros aspectos, expresa la proyección del disciplinamiento laboral consolidado en los años ' 90 . 
Hemos señalado, asimismo, que la negociación salarial, cuya centralidad caracteriza las negociaciones en el período reciente, partió de una profunda caída del salario real y no estuvo ajena a procesos de intensificación del tiempo de trabajo ya sea a partir de la (re)organización de turnos o de la (re)organización de tareas, si no que más bien en muchos casos se apoyó sobre dichos procesos de intensificación. En este sentido, frente a la recomposición y aumento de las ganancias capitalistas que se produce a partir de la devaluación, los trabajadores registrados más bien han recuperado o superado levemente los niveles salariales reales vigentes durante la convertibilidad, bajos en términos históricos.

Ahora bien, también observamos modificaciones puntuales en los contenidos de la negociación que pueden inscribirse en el marco de la puja distributiva desarrollada a partir del año 2005 al compás de la mayor conflictividad laboral y del protagonismo de la lucha sindical. Efectivamente, consideramos que la dinámica de la negociación colectiva en la argentina reciente ha funcionado como impulso de la organización de los trabajadores en sus lugares de trabajo y de una mayor implicancia en las prácticas sindicales.

A lo largo del período 2003-2015 es posible reconocer diferencias en las características de la negociación colectiva que manifiestan un aumento de la capacidad sindical de incorporar reivindicaciones y problemáticas en la mesa de negociación. Este reposicionamiento sindical, pese a encontrarse con una férrea resistencia empresaria y presentar diversas dificultades para plasmarse en los contenidos y resultados de la negociación, constituye una expresión de la activación de las bases obreras y del dinamismo de la negociación colectiva como canalización de los conflictos laborales en el período.

No es tan claro, en cambio, que este dinamismo de la actividad gremial en los lugares de trabajo implique una renovación de las prácticas gremiales. En este sentido, la permanencia de contenidos vinculados a la flexibilización laboral en la negociación colectiva o bien la negociación salarial a expensas de una intensificación de los ritmos de trabajo alertan sobre la orientación mayoritaria de los representantes sindicales.

Los límites y alcances de la organización de las bases obreras operado en el período 2003-2015, su vínculo con las dirigencias sindicales tradicionales, y el modo en que contribuyen a "normalizar" las relaciones laborales, o bien su vínculo con experiencias de sindicalismo antiburocrático y combativo, constituye un problema que se encuentra aún abierto al debate académico y político. 


\title{
AN OVERVIEW OF COLLECTIVE BARGAINING AND ITS RELATION WITH TRADE UNIONS IN ARGENTINA (2003-2015)
}

\begin{abstract}
Since the year 2003 in Argentina several studies have focused on the analysis of the political, institutional and economic determinants of collective bargaining, or on the study of its evolution and general characteristics. In spite of the importance of these dimensions, the analysis of the frequency of agreements and its evolution tends to displace, on one hand, theoretical discussions about collective bargaining and, on the other, the study of the contents and of negotiation processes. This paper aims to discuss theoretical elements and empirical results about collective bargaining during this period, and also to reflect on the link between bargaining processes and union organization during post-convertibility.
\end{abstract}

KEYWORDS: Collective Bargaining. Union organization. Industrial legality. Postconvertibility. Argentina.

\section{REFERENCIAS}

ACKERS, P. Collective bargaining as industrial democracy: Hugh Clegg and the political foundations of British Industrial Relations pluralism. British Journal of Industrial Relations, Vol. 45, No 1, 2007, p. 77-101.

ATZENI, M. y GHIGLIANI, P. The re-emergence of workplace based organisation as the new expression of conflict in Argentina. In: GALL, G. New Forms and Expressions of conflict at work. Palgrave Macmillan, 2013, p. 66-85.

. Nature and limits of trade unions' mobilisations in contemporary Argentina. Labour Again Publications, International Institute of Social History, Amsterdam, 2008. Disponible en $<$ http://www.iisg.nl/labouragain/documents/atzeni-ghigliani.pdf $>$. Acceso en: 12 jun. 2017.

CAMPOS, J. y CAMPOS, L. La negociación colectiva y el salario real: una aproximación al patrón de regulación de los salarios en la post convertibilidad (2003 - 2010). $\mathbf{1 0}^{\circ}$ Congreso Nacional de Estudios del Trabajo, Buenos Aires, ASET, 2011. Disponible en $<$ http://www. obderechosocial.org.ar/docs/nc_it_neg_sal_js2011.pdf $>$. Acceso en: 12 jun. 2017.

CLEGG, H. Sindicalismo en un sistema de negociación colectiva. Madrid: Ministerio de Trabajo y Seguridad Social, 1985. 
COTARELO, M. C. Argentina (1993-2010): El proceso de formación de una fuerza social, Buenos Aires: PIMSA-Imago Mundi, 2016.

. Movimiento sindical en Argentina 2004-2007: ¿Anarquía sindical? XI Jornadas Interescuelas/ Departamento de Historia, Universidad Nacional de Tucumán, 19 al 21 de septiembre, S. M. de Tucumán, 2007.

DABSCHECK, B. A survey of theories of industrial relations. In: BARBASH J. y BARBASH $\mathrm{K}$. (Ed.) Theories and concepts in comparative industrial relations, Columbia, South Carolina, University of South Carolina Press, 1989, p. 155-183.

ESKENAZI, M. E. Acumulación de capital y conflictividad laboral en Argentina 2002-2009: Ejercicio de periodización e hipótesis de trabajo. XXVIII Congreso ALAS, Recife, Brasil. Septiembre, 2011.

ETCHEMENDY, S. y COLLIER, R. Down but not out: union resurgence and segmented neocorporatism in Argentina (2003-2007). Politics \& Society. Vol. 35, No 3, Sage Publications, 2007, p. 363-401.

FLANDERS, A. y CLEGG, H. A. The system of industrial relations in Great Britain. Oxford: Basic Blackwell, 1956.

GRAMSCI, A. Escritos periodísticos de L'Ordine Nuovo. Buenos Aires: Tesis Once, 1991.

HYMAN, R. Relaciones Industriales: Una introducción marxista. Madrid: Blume Ediciones, 1981.

LONGO, J. Conflictos laborales en la postconvertibilidad: una aproximación a partir de fuentes periodísticas. VII Jornadas de Sociología de la Universidad Nacional de General Sarmiento, Los Polvorines, 2012. Disponible en $<$ http://www.ungs.edu.ar $/ \mathrm{ms}$ _ici/wpcontent/uploads/2012/11/gt2_mesa-2_Longo.pdf $>$. Acceso en: 12 jun. 2017.

MARTICORENA, C. Avances en el estudio de la relación entre sindicalismo y kirchnerismo, Sociohistórica. Cuadernos del CISH, $\mathrm{N}^{\circ}$ 36, Universidad Nacional de La Plata. Facultad de Humanidades y Ciencias de la Educación. Centro de Investigaciones Socio Históricas, 2015a, p. 22. Disponible en <http://www.sociohistorica.fahce.unlp.edu.ar/article/view/ SH2015n36a04>. Acceso en: 12 jun. 2017.

. Revitalización sindical y negociación colectiva en Argentina (2003-2011). Perfiles Latinoamericanos. $\mathrm{N}^{\circ} 46$, Facultad Latinoamericana de Ciencias Sociales - Sede México, 2015b, p. 173-195. Disponible en <http://perfilesla.flacso.edu.mx/index.php/perfilesla/article/ view/519>. Acceso en: 12 jun. 2017.

. Trabajo y negociación colectiva. Los trabajadores en la industria argentina, de los '90 a la posconvertibilidad. Editorial Imago Mundi, 2014a. 


\section{Un balance de la negociación colectiva y su relación con La organización sindical en Argentina (2003-2015)}

. Relaciones de fuerza, relaciones laborales y estructura de la negociación colectiva. Alcances y características de la descentralización en Argentina. Trabajo y Sociedad, $\mathrm{N}^{\circ} 23$, Universidad Nacional de Santiago del Estero, 2014b, p. 127-145. Disponible en $<$ http://www. unse.edu.ar/trabajoysociedad/23\%20MARTICORENA\%20CLARA\%20Relaciones\%20 laborales\%20y\%20negociacion\%20colectiva.pdf $>$. Acceso en: 12 jun. 2017.

Precariedad laboral y caída salarial. El mercado de trabajo en la Argentina Post convertibilidad. $7^{\circ}$ Congreso Nacional de Estudios del Trabajo, Buenos Aires, ASET, 2005.

MARTICORENA, C. y VASSALLO, D. ¿Sindicalismo de base en el sector químico? La experiencia del Sindicato Químico de Pilar. In: VARELA, P. (Coord.) EI gigante fragmentado: Sindicalismo, trabajadores y política durante el kirchnerismo. Buenos Aires: Editorial Final Abierto, 2016, p. 135-179.

NOVICK, M. y TRAJTEMBERG, D. La negociación colectiva en el período 1991-1999. Documento de Trabajo $\mathrm{N}^{\circ} 19$, Secretaría de Trabajo, Coordinación de investigaciones y análisis laborales. MTESS, Argentina, 2000.

OBSERVATORIO DEL DERECHO SOCIAL. La negociación colectiva 2003-2007. Un estudio comparativo con el período 1991-1999, en particular sobre la regulación de jornada y organización del trabajo. Observatorio del Derecho Social, Buenos Aires,

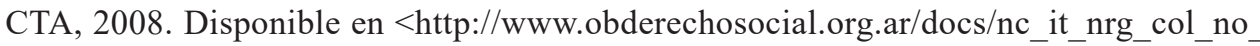
salarial_2003_2007.pdf >.Acceso en: 12 jun. 2017.

PALOMINO, H. y TRAJTEMBERG D. Una nueva dinámica de las relaciones laborales y la negociación colectiva en la Argentina. Revista de Trabajo, Año 2, N 3, MTEySS, Buenos Aires, 2006, p. 47-68. Disponible en $<$ http://www.trabajo.gov.ar/left/estadisticas/descargas/ revistaDeTrabajo/2006n03_revistaDeTrabajo/2006n03_a03_hPalomino.pdf $>$. Acceso en: 12 jun. 2017.

PAYO ESPER, M. De los conflictos laborales a las huelgas generales. Algunos apuntes para pensar su dinámica 2002-2012 en Argentina. Sociohistórica, n 33, $1^{\circ}$ Semestre de 2014. Disponible en $<$ http://www.sociohistorica.fahce.unlp.edu.ar/article/view/SH2014n33a03>. Acceso en: 12 jun. 2017.

SCHNEIDER, A. Protesta laboral y protesta obrera durante la presidencia de Néstor Kirchner (2003-2007)". In: GRIGERA J. (Comp.) La Argentina después de la convertibilidad (2002-2011). Buenos Aires: Imago Mundi, 2013, p. 97-113.

SENÉN GONZÁLEZ C., TRAJTEMBERG, D. y MEDWID B. Los determinantes de la egociación colectiva en la argentina. Debates teóricos y evidencias empíricas. Trabajo, ocupación y empleo. Serie Estudios/ 9, Buenos Aires, MTESS, 2010, p. 13-35. Disponible 
en <http://www.trabajo.gov.ar/left/estadisticas/descargas/toe/toe_09_completo.pdf $>$. Acceso en: 12 jun. 2017.

SPALTENBERG, R. La diversidad de los conflictos laborales: dispersión y centralización en las lógicas de acción de los asalariados privados. Trabajo, ocupación y empleo, $\mathrm{N}^{\circ}$ 11, MTESS, 2012, p. 95-118. Disponible en <http:/www.trabajo.gov.ar/left/estadisticas/ descargas/toe/Toe11_Capitulo\%204.pdf>. Acceso en: 12 jun. 2017.

TRAJTEMBERG, D., BERHÓ, F., ATTORRESSI, P. y LAUPHAN W. Encuesta de Relaciones Laborales, $7^{\circ}$ Congreso Nacional de Estudios del Trabajo, ASET, Buenos Aires, 2005.

TRAJTEMBERG, D., B. MEDWID y SENÉN GONZÁLEZ C. La expansión de la afiliación sindical: Análisis del módulo de relaciones laborales de la EIL. Trabajo, ocupación y empleo, Serie Estudios/ 8, Buenos Aires, MTESS, 2009, p. 13-34. Disponible en <www. trabajo.gov.ar/left/estadisticas/descargas/toe/toe_08_01.pdf>. Acceso en: 12 jun. 2017.

TRAJTEMBERG, D., SENÉN GONZÁleZ, C., BORRONI, C. y G. PONTONI, Representación sindical en los lugares de trabajo: un análisis del Módulo de Relaciones laborales. Trabajo, ocupación y empleo, $N^{\circ} 11$, MTESS, 2012, p. 119-141. Disponible en <www.trabajo.gov.ar/left/estadisticas/descargas/.../Toe11_Capitulo\%205.pdf>. Acceso en: 12 jun. 2017.

VARELA, P. (Coord.) El gigante fragmentado. Sindicalismo, trabajadores y política durante el kirchnerismo. Buenos Aires: Editorial Final Abierto, 2016.

VARELA, P. La disputa por la dignidad obrera. Sindicalismo de base fabril en la zona norte del Conurbano bonaerense 2003-2014. Buenos Aires: Imago Mundi, 2015.

. El sindicalismo de base en la Argentina postdevaluación. Hipótesis sobre sus alcances y potencialidades. In: GRIGERA J. (Comp.) La Argentina después de la convertibilidad (2002-2011). Buenos Aires: Imago Mundi, 2013, p. 115-133.

Recebido em 14/03/2016.

Aprovado em 14/06/2017. 